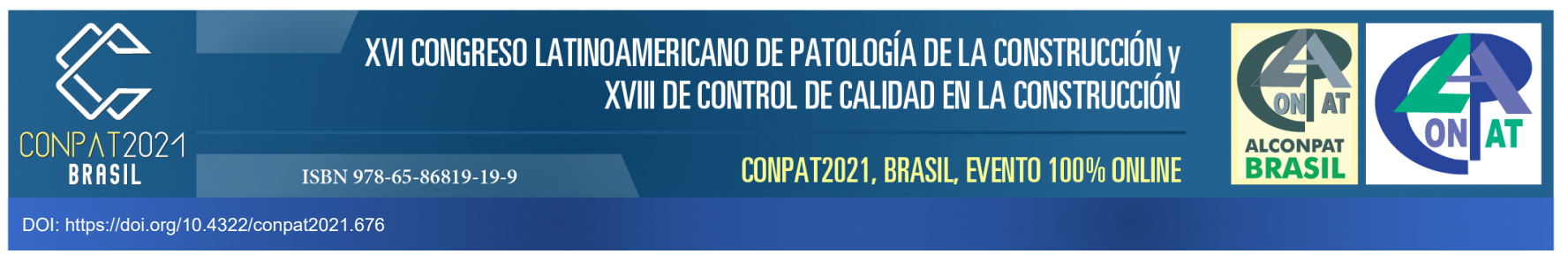

\title{
Elaboração de mapas de danos e a influência de intempéries em fachadas: Estudo de caso no Prédio de Pós-Graduação em Letras da Universidade Federal do Pará.
}

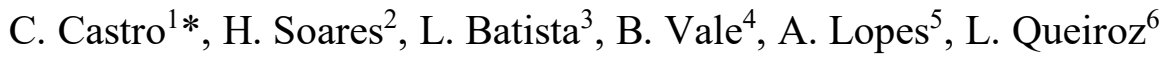 \\ *Autor de Contato: murillosc@gmail.com \\ 1,2,3,4,5,6 Faculdade de Engenharia Civil, ITEC, Universidade Federal do Pará, Belém, Brasil
}

\begin{abstract}
RESUMO
Devido ao processo de degradação de revestimentos de fachadas e à importância de investigação desse processo, o presente trabalho teve o objetivo de identificar as principais manifestações patológicas nas fachadas de uma edificação e criar Mapas de Danos (MDs), assim como verificar a influência de intempéries nesse processo. Para tal, foi realizada inspeção pelo método indireto no Prédio de Pós-Graduação em Letras da Universidade Federal do Pará e elaboradas Fichas de Identificação de Danos (FIDs), além da coleta de dados de vento e precipitação de chuva na região. Como resultados, foi possível elaborar os MDs e obter a relação entre a ação de intempéries com as fachadas que apresentavam as maiores incidências de manifestação patológica no revestimento.
\end{abstract}

Palavras chave: Mapa de danos; manifestação patológica; revestimento; fachada; inspeção predial.

\section{ABSTRACT}


Due to the degradation process of facade coatings and the importance of investigating this process, the present work aimed to identify the main pathological manifestations on the façades of a building and create Damage Maps (MDs), as well as verify the influence of weathering. in this process. For this purpose, inspection was carried out using the indirect method at the Postgraduate Course in Languages at the Federal University of Pará and Damage Identification Sheets (FIDs) were prepared, in addition to the collection of wind and rain data in the region. As a result, it was possible to elaborate the MDs and obtain the relationship between the action of weathering and the façades that presented the highest incidences of pathological manifestations in the coating.

Keywords: Damage map; pathological manifestation; coating; facade; building inspection.

\section{RESUMEN}

Debido al proceso de degradación de los revestimientos de fachadas y la importancia de investigar este proceso, este estudio tuvo como objetivo identificar las principales manifestaciones patológicas en las fachadas de un edificio y crear Mapas de Daños (MDs), así como verificar la influencia de la meteorización en. este proceso. Para ello, se realizó la inspección mediante el método indirecto en el Posgrado en Idiomas de la Universidad Federal de Pará y se elaboraron Fichas de Identificación de Daños (FID), además de la recolección de datos de viento y lluvia en la región. Como resultado, fue posible elaborar los MD y obtener la relación entre la acción de la intemperie y las fachadas que presentaban las mayores incidencias de manifestaciones patológicas en el revestimiento.

Palabras clave: Mapa de daños; manifestación patológica; revestimiento; fachada; inspección de edificios.

\section{INTRODUÇÃO}

As fachadas de uma edificação, além de estética, apresentam a função de proteger os elementos de internos dos edifícios da ação direta dos agentes agressivos, auxiliando as vedações no cumprimento de suas funções quanto ao desempenho e à regularização da superfície, servindo de base adequada ao recebimento de outros revestimentos ou constituir-se no acabamento final (Baía e Sabbatini, 2008). Dessa forma, é fundamental que o sistema de fachadas apresente durabilidade adequada, para que o mesmo tenha vida útil compatível com o esperado pelo projeto.

Entretanto, ao longo de sua vida útil, as fachadas estão sujeitas a um processo complexo de degradação de agentes externos provenientes de diferentes naturezas, agindo de forma associada ou não. Quanto aos agentes de degradação, eles podem ser provenientes de fatores climáticos (radiação, água, vento e contaminantes do ar), biológicos, mecânicos e de incompatibilidades (Santos, 2018). Além desses fatores, ressalta-se a importância da manutenção, visto que muitos edifícios não recebem manutenções preventivas e/ou corretivas, a fim de minimizar a ação desses fatores e agentes e, assim, evitar a proliferação de manifestações patológicas.

Segundo Gonçalves (2015), as manifestações patológicas são definidas como todas as manifestações cuja ocorrência no ciclo de vida da edificação venha prejudicar o desempenho esperado do edifício e suas partes. No sistema de revestimento de fachadas, a incidência das manifestações é geralmente acelerada pelo tipo de materiais utilizados e dos detalhes arquitetônicos da edificação, tornando o descolamento, fissura, manchas, pulverulência e eflorescência as manifestações mais comuns (Madureira et al., 2017). 
Nesse sentido, a realização de inspeções, avaliações e a elaboração de possíveis diagnósticos são fundamentais para a identificação precoce de potenciais problemas em uma edificação, possibilitando o planejamento de uma manutenção preventiva. Em casos de manifestações patológicas no revestimento das fachadas, as inspeções e diagnósticos são essenciais para auxiliar no processo de intervenção, evitando o agravamento e buscando o entendimento das causas (Gonçalves; Brito; Amaro, 2007).

Após feita a inspeção e identificada alguma situação anômala ou danos mais críticos, para que possa haver uma análise mais minuciosa, são gerados documentos acerca das manifestações observadas. Entre esses documentos, está o mapa de danos que consiste em uma ferramenta que possibilita a investigação do estado de conservação de uma edificação, por meio de registros gráficos dos levantamentos realizados e identificados (Costa, 2014). Apesar de ainda não haver uma normatização que determine qual o melhor procedimento para ser seguido na construção de mapas de danos, a metodologia indicada pelo Instituto do Patrimônio Histórico e Artístico Nacional (IPHAN) é uma das mais utilizadas durante o processo de documentos.

Diante do exposto e da necessidade da Prefeitura Multicampi da Universidade Federal do Pará em fazer um levamento das manifestações patológicas nas fachadas dos prédios da universidade, o presente trabalho apresenta um estudo de caso no prédio de Pós-Graduação em Letras, que foi escolhido para inspeção devido ao curto período de construção e à elevada quantidade de anomalias encontradas. Foi realizada a inspeção preliminar que buscou identificar visualmente as degradações existentes nas fachadas da edificação, assim como a análise dos elementos arquitetônicos e a ação de intempéries que possam influenciar na aceleração do surgimento dessas manifestações. A partir disso, foi construído o mapa de danos que pode servir como ferramenta para auxiliar em posteriores intervenções da Prefeitura Multicampi nesse prédio.

\section{METODOLOGIA}

\subsection{Características gerais da edificação}

O Prédio do Programa de Pós Graduação em Letras (PPGL) localiza-se na cidade de Belém-PA, no Campus Guamá, setor Básico da Universidade Federal do Pará, na latitude $1^{\circ} 28^{\prime} 47^{\prime}$ ' e longitude 48²7'23'. Inaugurado em 13 de dezembro de 2019, o prédio abriga atividades dos Institutos de Letras e Comunicação (ILC) e de Filosofia e Ciências Humanas (IFCH), e comporta uma estrutura com pavimento térreo mais três pavimentos, como indicado nas Figuras 01 e 02.

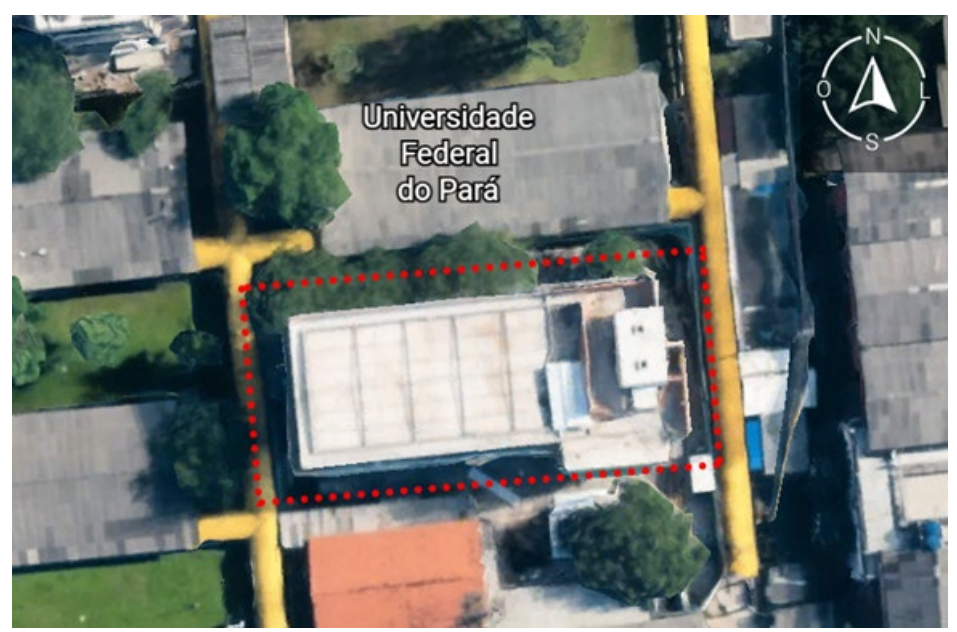

Figura 1. Localização do Prédio de Pós-Graduação em Letra (Google Maps). 


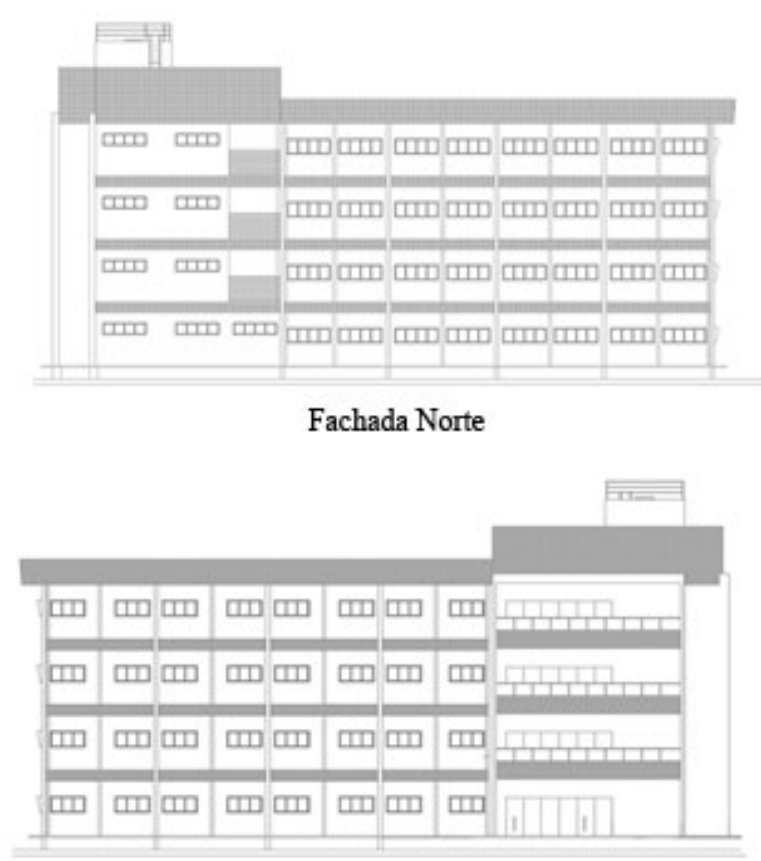

Fachada Sul

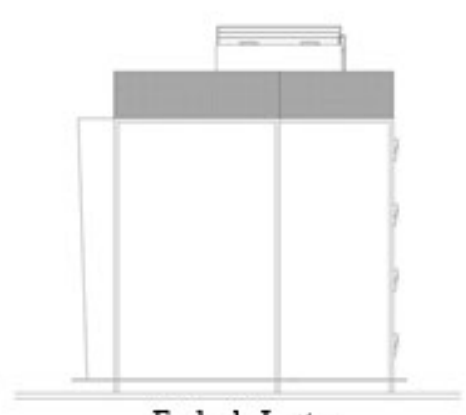

Fachada Leste

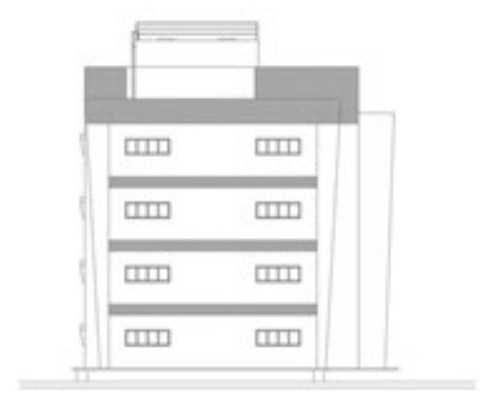

Fachada Oeste

Figura 2. Projetos das fachadas da edificação.

Quanto às fachadas, de acordo com os projetos disponibilizados e com o que foi observado in loco, o sistema conta com revestimento do tipo cerâmico, acabamento em pintura e concreto aparente. Dessa forma, para o revestimento cerâmico, a recomendação indicava a utilização de pastilhas cerâmicas de $10 \times 10 \mathrm{~cm}$, para o revestimento com acabamento em pintura a utilização de tinta PVA acrílica e nas áreas de concreto aparente a aplicação de verniz. Segundo a Prefeitura Multicampi da Universidade, as fachadas foram executadas no início do ano de 2017.

Além disso, as fachadas referentes às direções Norte $(\mathrm{N})$, Sul $(\mathrm{S})$ e Oeste $(\mathrm{O})$ apresentam janelas e balancins em vidro temperado com moldura em concreto com pintura PVA acrílica. $\mathrm{Na}$ fachada referente à direção sul, o sistema conta também com uma porta de abrir de vidro temperado incolor.

\subsection{Inspeção e mapa de danos}

A inspeção no Prédio de Pós-Graduação em Letras ocorreu pelo método indireto que, segundo Tinoco (2009), corresponde às investigações que são realizadas de maneira analítica, a partir da interpretação de documentos escritos, gráficos, iconográficos e testemunhos orais, que possam fundamentar hipóteses e conclusões. Assim, para início da inspeção, foram buscadas informações sobre o prédio de estudo. Tais informações foram fornecidas pela Prefeitura Multicampi da Universidade Federal do Pará, como especificações técnicas de execução, projeto arquitetônico, fotos da época da construção da edificação e valor de obra.

Dessa forma, para a obtenção de dados, foi realizada a visita in loco, que ocorreu no dia 17/06/2021, às 9:00h da manhã, onde foi realizado o registro fotográfico da edificação, assim como das principais manifestações patológicas encontradas no edifício.

Além da identificação das manifestações patológicas e dos registros fotográficos das fachadas, foi fundamental a elaboração de uma Ficha de Identificação de Danos (FID). A FID é o registro 
principal para a construção do Mapa de Dano (MD) e corresponde a um documento normalizado com registro e anotações gráficas e fotográficas sobre os danos existentes em uma edificação (TINOCO, 2009).

O Mapa de Dano foi elaborado no software da Autodesk (Autocad) e também com auxílio do Adobe Photoshop CC, com o objetivo da Prefeitura Multicampi em fazer um levantamento das manifestações mais recorrentes nos prédios da universidade e, com isso, realizar futuras intervenções.

\subsection{Análise da exposição às intempéries}

Após a elaboração dos mapas de danos, buscou-se investigar o surgimento de algumas das manifestações patológicas presentes nas fachadas, dando prioridade para os manchamentos, que causam maior impacto visual negativo para quem observa a edificação. Por se tratar de manchamento por umidade, buscou-se analisar dados envolvendo ventos e chuvas.

Os dados coletados para análise da ação pluviométrica nas fachadas do prédio foram coletados a partir do banco de dados do Instituto Nacional de Meteorologia (INMET). Os dados correspondem às precipitações na cidade de Belém/PA, no período de 2017 a 2020. Foi gerada uma base de dados referentes a essas medições de hora em hora nas estações, onde foram removidos valores com erros de leitura, ventos sem precipitação e ventos com velocidades menores que $1 \mathrm{knot}(0,5 \mathrm{~m} / \mathrm{s})(\mathrm{MELO}$ JUNIOR e CARASEK, 2011).

Os dados da direção do vento, que é registrado em graus, foram convertidos para as coordenadas N, NL, L, SL, S, SO, O e NO, conforme a Tabela 1. Também foi calculada a frequência de ocorrência dos ventos e sua velocidade média, conforme condições adotadas.

Tabela 1. Conversão da direção do vento em coordenadas.

\begin{tabular}{|c|c|}
\hline DIREÇÃO DO VENTO $\left(^{\circ}\right)$ & COORDENADAS \\
\hline $337,5^{\circ} \leq \mathrm{x}<22,5^{\circ}$ & Norte $(\mathrm{N})$ \\
\hline $22,5^{\circ} \leq \mathrm{x}<67,5,5^{\circ}$ & Nordeste (NL) \\
\hline $67,5^{\circ} \leq \mathrm{x}<112,5^{\circ}$ & Leste $(\mathrm{L})$ \\
\hline $112,5^{\circ} \leq \mathrm{x}<157,5^{\circ}$ & Sudeste (SL) \\
\hline $157,5^{\circ} \leq \mathrm{x}<202,5^{\circ}$ & Sul (S) \\
\hline $202,5^{\circ} \leq \mathrm{x}<247,5^{\circ}$ & Sudoeste (SO) \\
\hline $247,5^{\circ} \leq \mathrm{x}<292,5^{\circ}$ & Oeste (O) \\
\hline $292,5^{\circ} \leq \mathrm{x}<337,5^{\circ}$ & Noroeste (NO) \\
\hline
\end{tabular}

\section{RESULTADOS E DISCUSSÃO}

A partir da metodologia empregada, com base na inspeção e nos dados obtidos por meio dos registros fotográficos, pôde-se produzir, primeiramente, as Fichas de Identificação de Danos (FIDs).

As FIDs foram fundamentais para obtenção de uma visão geral das principais manifestações patológicas encontradas no revestimento do prédio estudado e, assim, permitiram uma análise pontual de cada fachada, sendo identificadas as degradações que comprometem a integridade física e estética da edificação. 
A primeira FID é referente à fachada norte da edificação. Foi possível observar diversas áreas com manchas de coloração laranja, verde e preta. Observou-se que onde havia menor exposição ao sol por conta de árvores existentes, havia maior proliferação do agente causador do manchamento de tom laranja, enquanto os pavimentos superiores apresentaram a predominância dos manchamentos de tom escuro. É importante citar que estes manchamentos ocorreram apenas nas áreas pintadas com tinta branca.

Nesta fachada foi identificada uma maior quantidade de empolamentos nas áreas dos pilares, todos no intervalo entre o térreo e o primeiro pavimento.

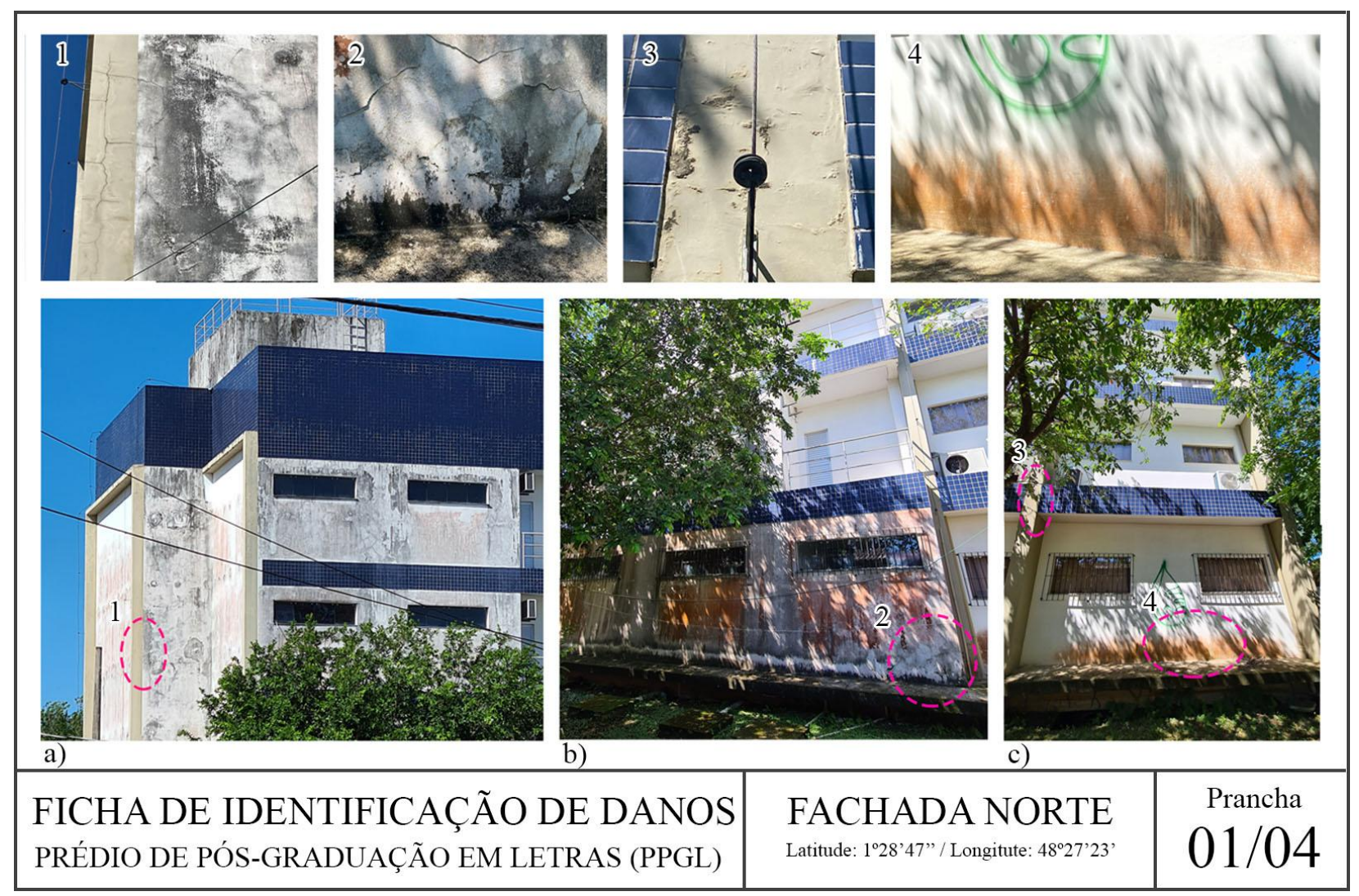

Figura 3. FID da fachada norte. Fonte: Autores (2021)

A fachada leste é a que possui menos elementos arquitetônicos que possam diminuir o efeito de intempéries. Assim, entre todas as fachadas, é a que tem o visual mais poluído por manchamento de cores escuras (pretas) e alaranjadas, assim como a fachada norte, porém, de menor intensidade na cor laranja.

Por ser a fachada mais exposta, foi observado que os manchamentos ocorrem somente nos trechos onde foi realizado o acabamento em pintura na cor branca, o que levanta a hipótese de erro construtivo e que não foi utilizada a recomendação técnica adequada de pintura para o ambiente, sugerida pela Prefeitura Multicampi. Além disso, houve a identificação de manchamento causado por eflorescência em certos pontos do revestimento cerâmico e a formação de fissuras geométricas, como indica a Figura 4. 


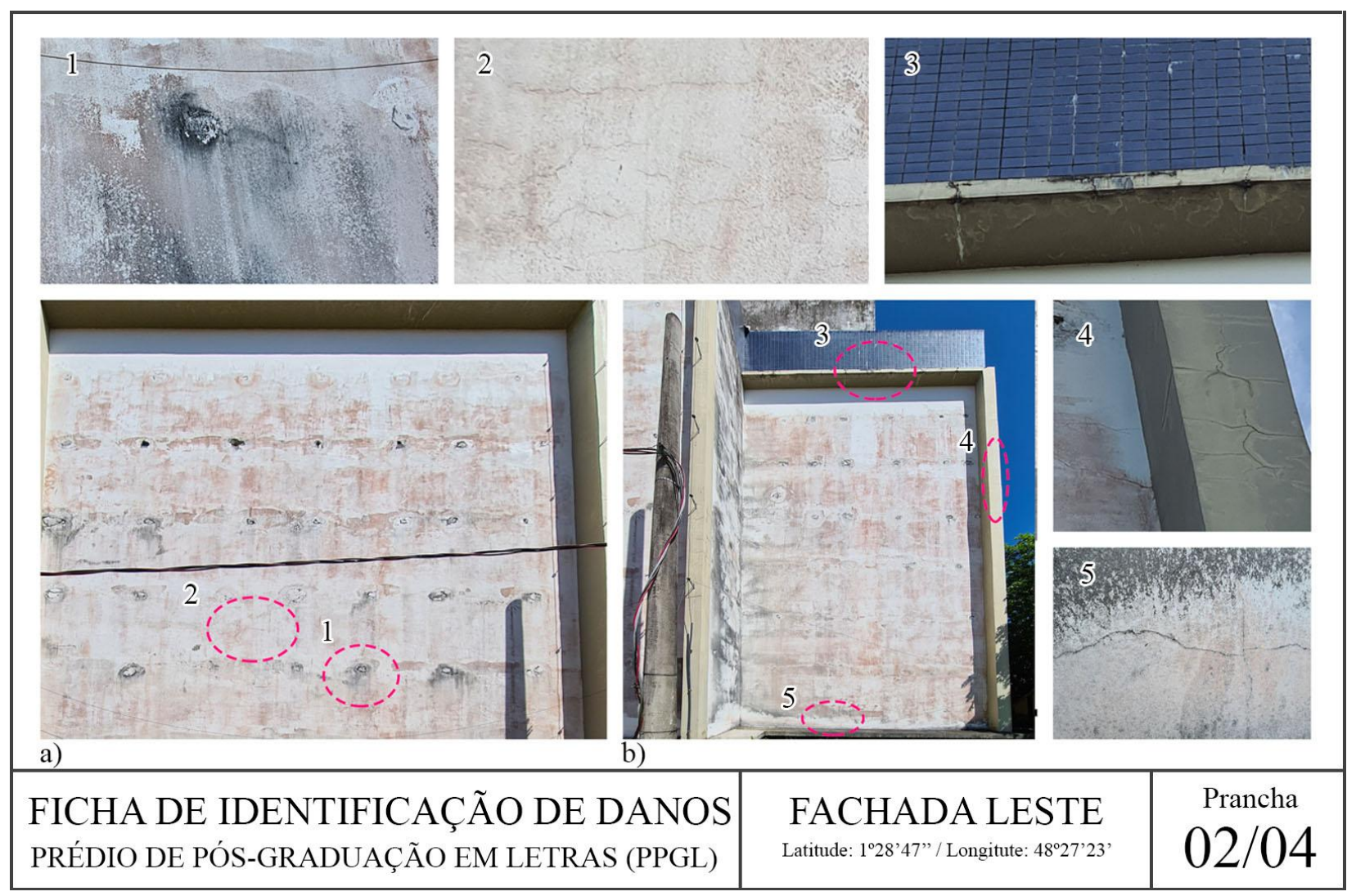

Figura 4. FID da fachada leste. Fonte: Autores (2021).

Com base na Figura 5, a FID da fachada sul indicou que a região apresentava manchamento no seu lado direito, onde não existe detalhe construtivo que proteja a fachada contra a chuva, e na direção de um dreno de ar condicionado, instalado de forma incorreta, provocando as manchas de umidade e poluindo visualmente a fachada com o dreno exposto. Além disso, foi verificado que não houve preocupação estética nos locais em que os ar condicionados foram instalados, visto que a alvenaria estava exposta.

As fissuras identificadas adotam um padrão. Entre o segundo e terceiro pavimento, foi possível localizar a presença de fissuras horizontais nos pilares e fissuras verticais abaixo do peitoril na maioria das esquadrias. Outra manifestação patológica presente na fachada foi o manchamento causado por eflorescência. 


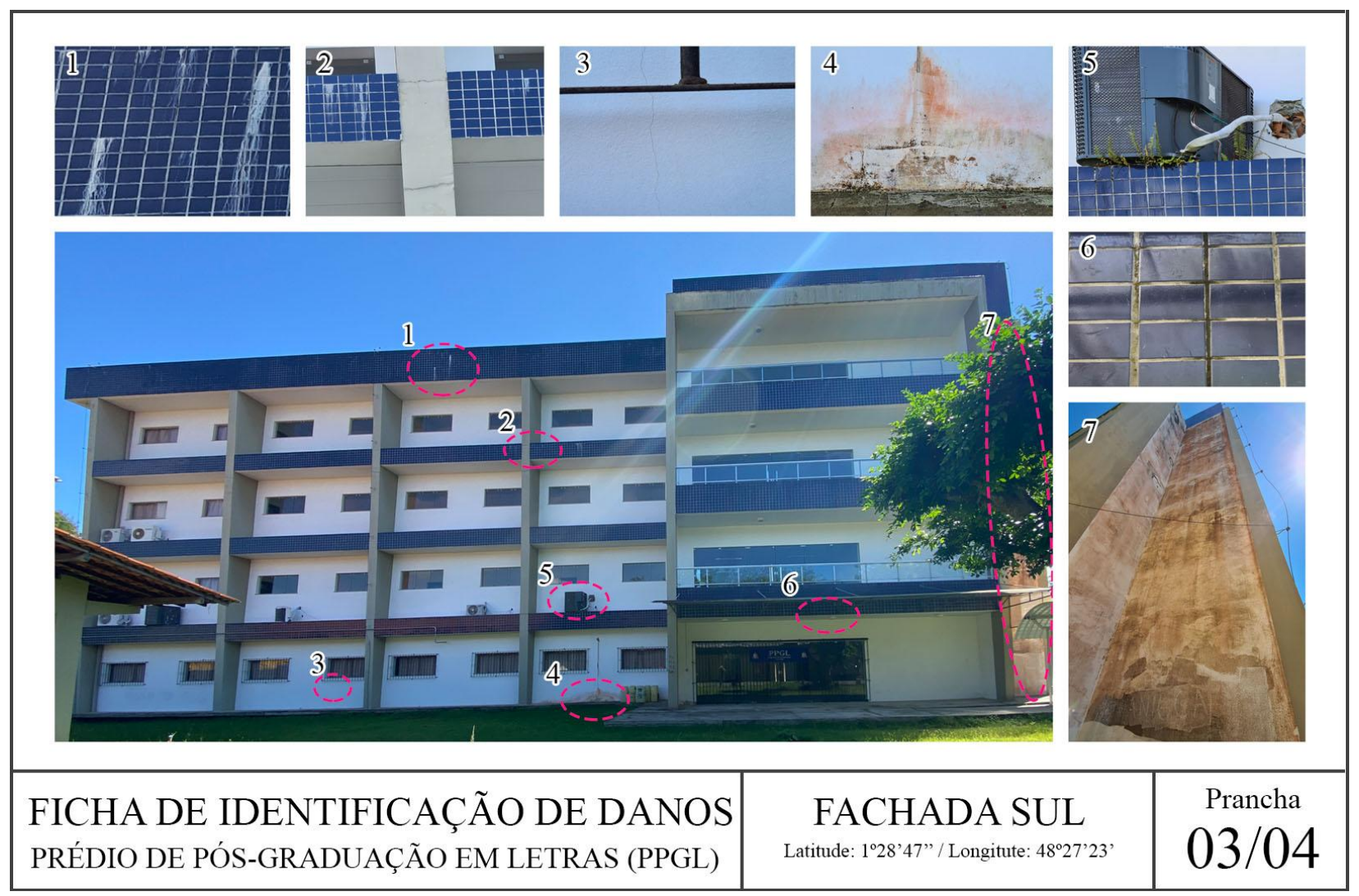

Figura 5. FID da fachada sul. Fonte: Autores (2021).

A fachada oeste, quando comparada com as demais, apresentou menor quantidade de manifestações por intempéries. Porém, existem partes desta fachada onde não há elementos arquitetônicos que protejam contra agentes de degradação, como é possível ver na Figura 06, nos detalhes a) e c). Foi possível notar um manchamento causado por umidade vindo do peitoril, que apesar de instalado, não segue as recomendações da NBR 10821 (ABNT, 2017) para esquadrias externas de uma edificação, a qual sugere uma borda e inclinação de peitoril maior, para que a água não escorra pelas bordas e cause possíveis manchamentos. 


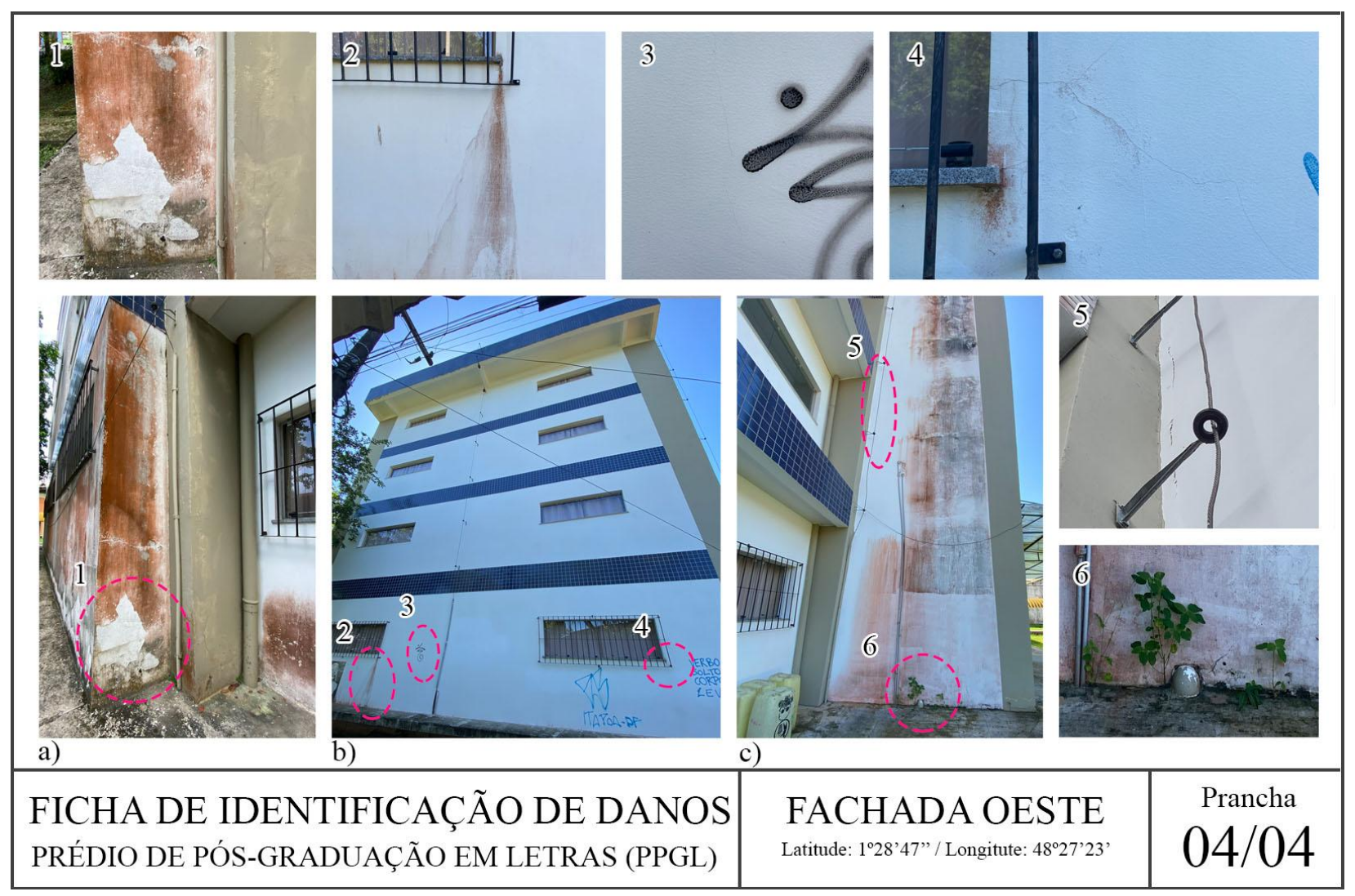

Figura 6. FID da fachada oeste. Fonte: Autores (2021).

Com o auxílio das fichas de identificação de danos, do projeto arquitetônico do edifício, dos registros fotográficos, de documentos da obra, realizou-se a elaboração dos mapas de danos das fachadas. Buscou-se utilizar na projeção deste mapa, elementos nas legendas que, ao sobrepor outro elemento, não ocultasse a manifestação patológica, pois duas ou mais patologias podem ocorrer simultaneamente em uma mesma área. A intenção da utilização destas legendas é de deixar o mapa mais didático, de fácil compreensão.

Como foi possível verificar nas FIDs, algumas fachadas não possuem registros fotográficos da fachada inteira, devido à limitação dos equipamentos de inspeção, da presença de árvores e também de outras edificações próximas que impossibilitam a captura de toda a fachada. Diante destas situações o mapa de danos se mostra bastante eficaz, pois auxilia na organização e visualização dos dados coletados, alocando de forma prática as patologias identificadas nas fachadas.

As Figuras 7, 8, 9 e 10 ilustram os mapas de danos elaborados para o edifício de estudo. Os mapas de danos foram elaborados para cada uma das fachadas: norte, leste, sul e oeste. 


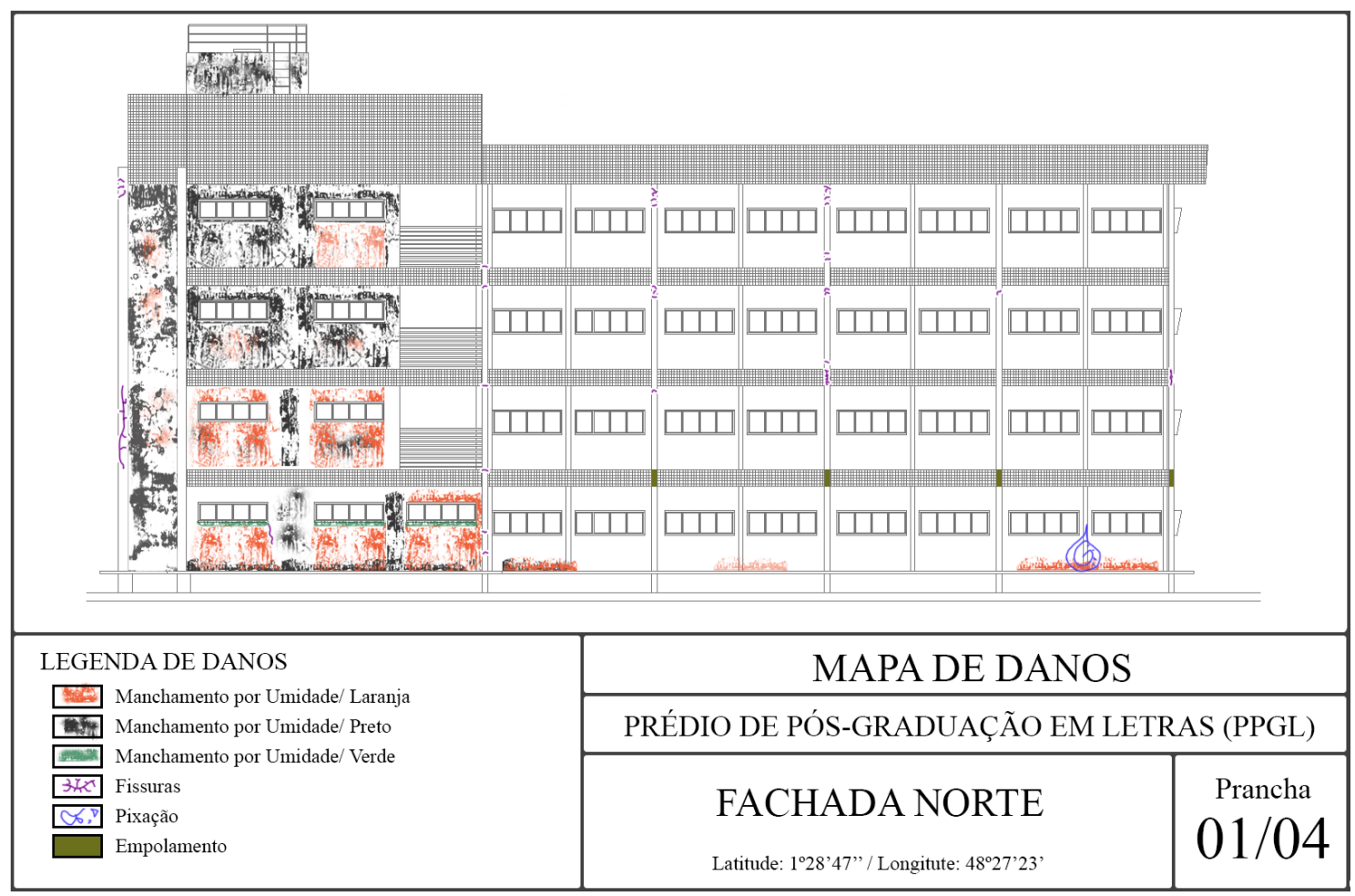

Figura 7. MDs da fachada norte. Fonte: Autores (2021).

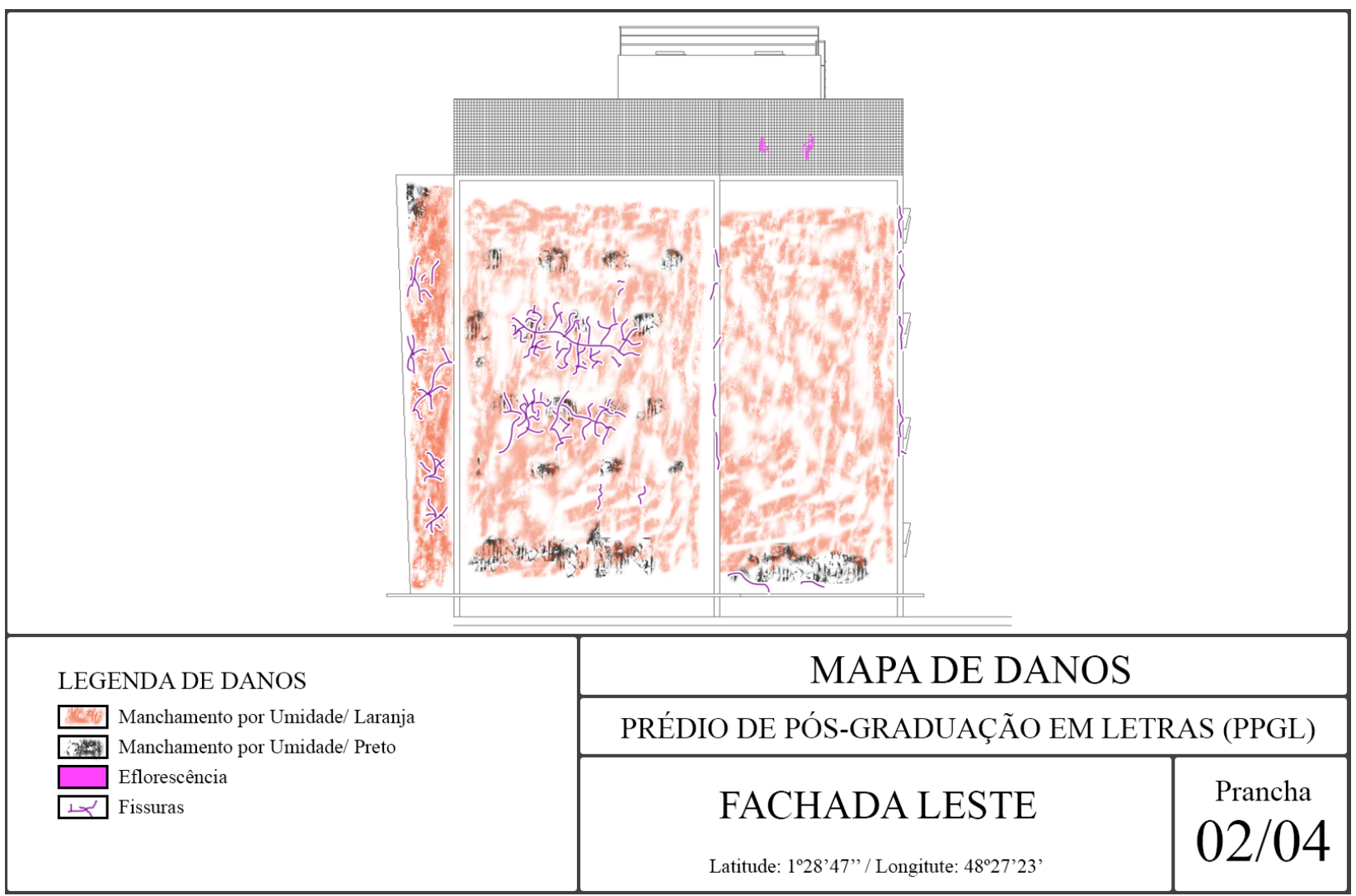

Figura 8. MDs da fachada leste. Fonte: Autores (2021). 


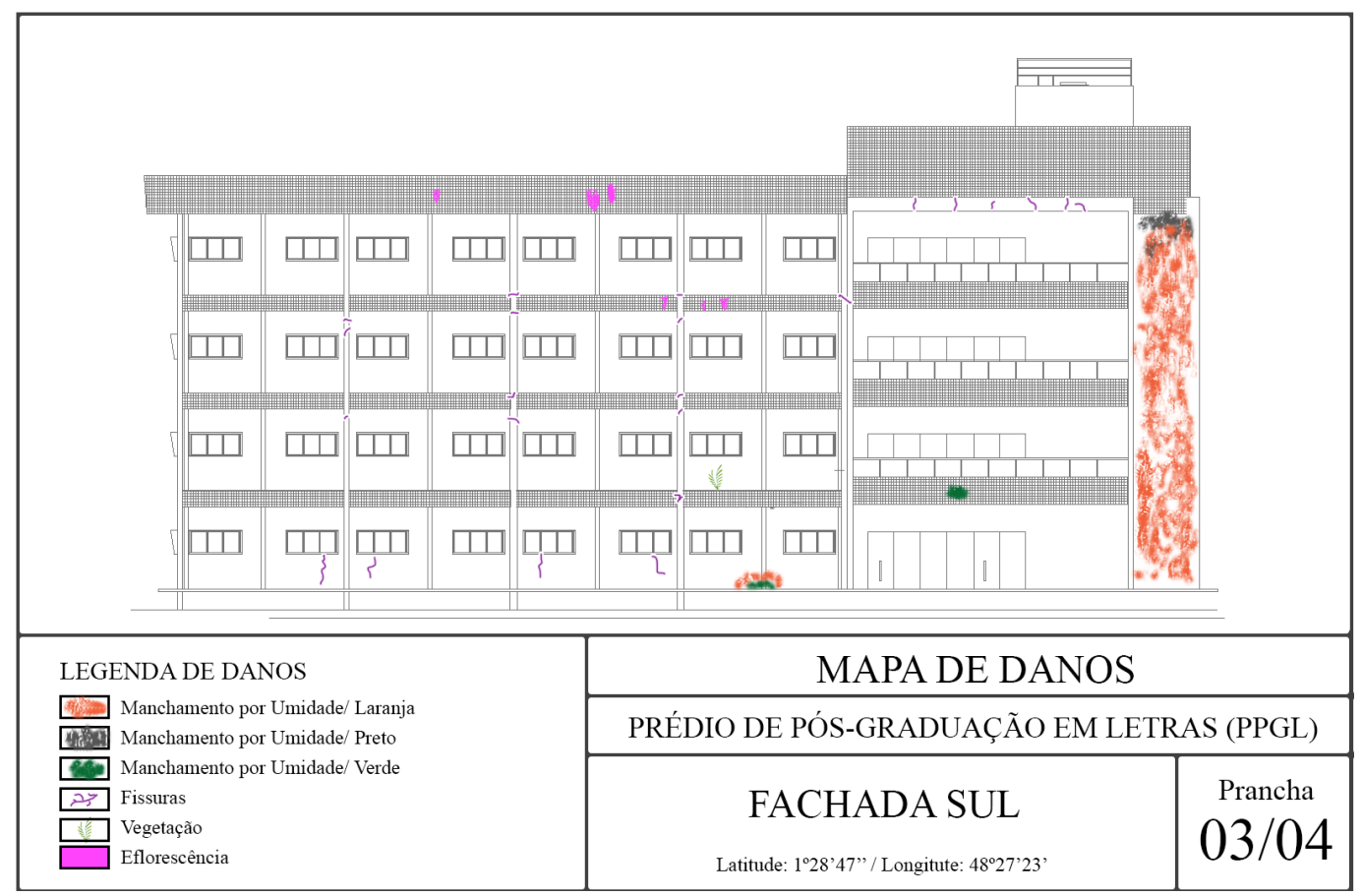

Figura 9. MDs da fachada sul. Fonte: Autores (2021).

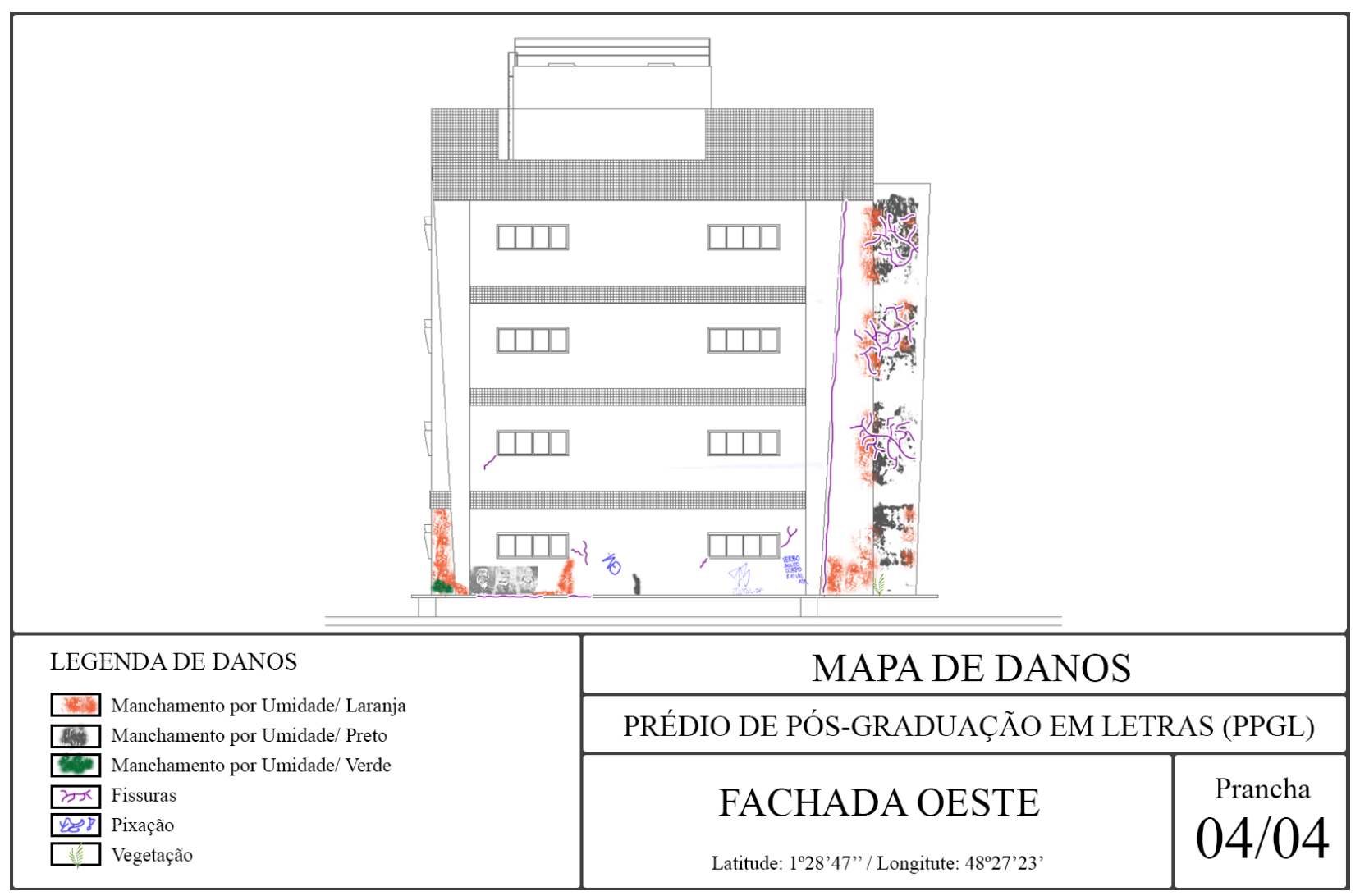

Figura 10. MDs da fachada sul. Fonte: Autores (2021). 
Quanto aos resultados da ação do vento e precipitação de chuva em cada direção, obtidos do banco de dados do INMET, foi possível analisar a influência desses agentes nas fachadas da edificação. Segundo os dados, conforme Figura 11, entre os anos 2017 e 2020, a velocidade média do vento não apresentou grande variação nas direções correspondentes às que as fachadas são localizadas. Em relação à precipitação pluviométrica, foi possível identificar que, ao longo dos anos, houve um volume maior de chuva entre as direções norte e sudeste. Assim, as fachadas que correspondem a essas direções foram as que tiveram maior impacto da ação dessa intempérie.
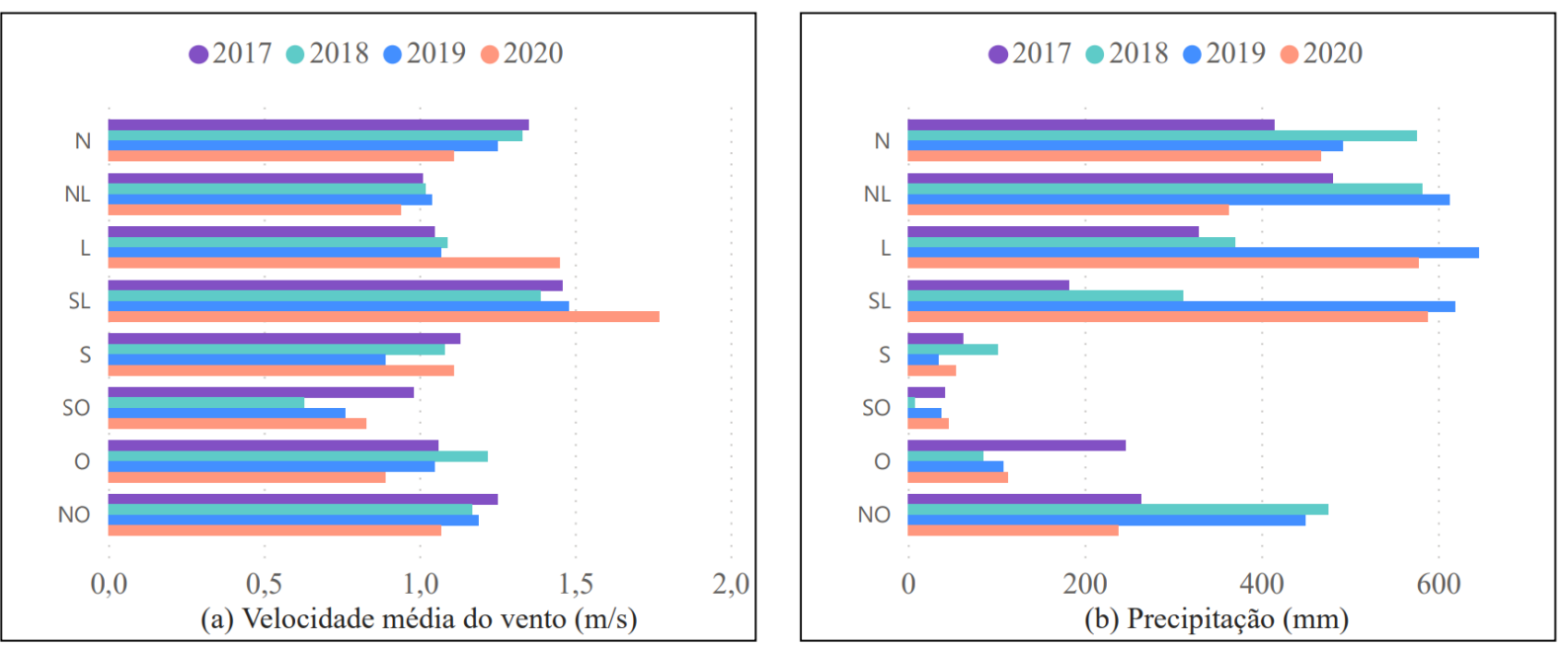

Figura 11. a) Velocidade média do vento entre 2017 e 2020 em cada direção. b) Precipitação pluviométrica entre os anos 2017 e 2020 em cada direção.

Dessa forma, foi possível elaborar um gráfico da frequência de vento em cada direção e, com isso, analisar a associação desse fator com a precipitação pluviométrica. Como resultado, assim como a precipitação de chuva, a frequência de vento foi maior para as regiões que compreendem as coordenadas entre as direções norte e sudeste, como indicado na Figura 12.

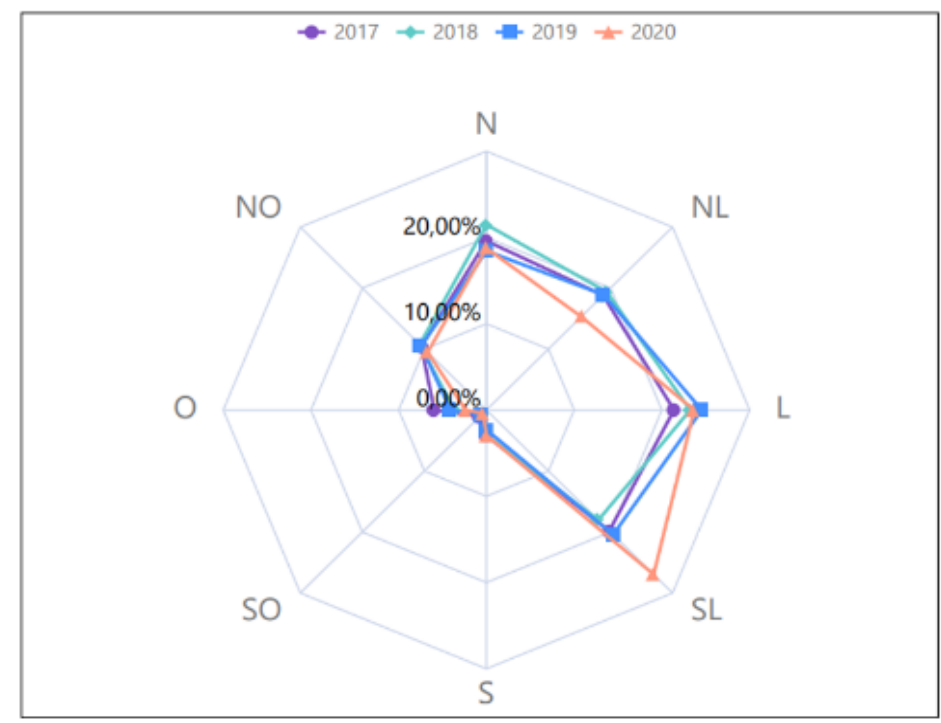

Figura 12. Frequência de vento em cada direção entre 2017 e 2020. Fonte: Autores (2021). 
Segundo Van Mook (2002), esse tipo de associação entre vento e precipitação pluviométrica gera o fenômeno conhecido como chuva dirigida, o qual a precipitação carregada pelo vento é direcionada para as fachadas das edificações. Dessa forma, as fachadas que estiverem voltadas para os ventos predominantes estarão mais expostas e receberão uma maior quantidade de chuva. Diante desse efeito, as regiões que estão mais sujeitas a esse tipo de fenômeno desencadeiam uma variedade de manifestações patológicas causadas pela presença de umidade. De acordo com Bertolini (2010), o excesso de umidade nos revestimentos das fachadas favorece a degradação do revestimento por interações do tipo físicas, químicas e/ou biológicas, resultando em ocorrências de fissuras, manchamento, biodeterioração e eflorescência.

Nessa perspectiva, foi possível relacionar a maior ocorrência de manchamentos das fachadas leste e norte com a maior frequência de chuvas direcionadas pelo vento nessas regiões. Além disso, foi verificado que tais ocorrências de manchamentos foram intensificados pela ausência de elementos arquitetônicos que pudessem proteger as fachadas da ação pluviométrica, evitando a proliferação de manifestações patológicas.

\section{CONCLUSÃO}

Levando em consideração a exposição das fachadas com revestimento em argamassa, geralmente são encontradas manifestações patológicas causadas por agentes de degradação que atingem a integridade física e estética de uma edificação. Tais manifestações são comumente proliferadas pela ação de intempéries, como chuva e vento, e pela ausência de elementos arquitetônicos, que possam auxiliar na atenuação das ocorrências de degradação.

Dessa forma, tem-se como fator importante a realização periódica de inspeções em edificações, para que as manifestações patológicas possam ser identificadas e, com isso, a elaboração de tratamentos corretivos e/ou preventivos. Tais medidas são consideradas fundamentais, visto que por meio da realização das mesmas a edificação pode ter o seu tempo de vida útil prolongado.

Assim, o presente trabalho atingiu o seu objetivo em identificar as principais manifestações patológicas nos revestimentos das fachadas do Prédio de Pós-Graduação da Universidade Federal do Pará, por meio da elaboração de Fichas de Identificação de Danos (FIDs). Tal método foi considerado satisfatório visto que, por meio do mesmo, foi possível ter uma visão global das principais áreas degradadas de cada fachada com a criação de Mapa de Danos (MDs), servindo de base para futuras intervenções corretivas.

Além disso, por meio dos resultados de vento e chuva obtidos, foi possível relacionar tais agentes com as regiões mais degradadas. As fachadas norte e leste, foram as que apresentaram as maiores áreas de manchamento por umidade no prédio. Tal ocorrência deve-se às maiores incidências de chuva dirigida que aconteceram nas mesmas direções, preferencialmente na região compreendia entre as direções norte e sudeste.

Nessa perspectiva, percebe-se que com esta identificação das manifestações patológicas, criação de mapa de danos e análise da ação de intempéries, conseguem-se resultados satisfatórios e consistentes para o levantamento de possíveis diagnósticos e, com isso, intervenção de uma área degradada, objetivando a realização de manutenções que possam dar qualidade à estética e ao sistema de revestimento de uma edificação. 


\section{REFERÊNCIAS BIBLIOGRÁFICAS}

Associação Brasileira de Normas Técnicas. (2017). NBR 10821: Esquadrias para edificações. Rio de Janeiro.

Baía, L. L. M., Sabbatini, F. H. Projeto e Execução de Revestimentos de Argamassa. 4a Ed. São Paulo: Nome da Rosa, (Coleção primeiros passos da qualidade no canteiro de obras). 2008, 89 p.

Bertolini, L. Materiais de construção: patologia, reabilitação, prevenção. Tradução por Leda Maria Marques Dias Beck. São Paulo: Oficina de Textos, 2010.

Costa, M. S. Identificação de Danos em Fachadas de Edificações por meio de Imagens Panorâmicas Geradas por Plataforma Robótica Fotográfica. Dissertação de Mestrado em Estruturas e Construção Civil, Publicação E.DM-007/14, Departamento de Engenharia Civil e Ambiental, Universidade de Brasília, Brasília, DF, 2014, 184p.

Gonçalves, A., Brito, J., Branco, F. Reabilitação de paredes de alvenaria revestidas. In: $2^{\circ}$ Congresso Nacional de Argamassas de Construção Anais..., Lisboa. 2007.

Gonçalves, E. A. B. Estudo De Patologias E Suas Causas Nas Estruturas De Concreto Armado De Obras De Edificações. Trabalho de Conclusão de Curso. UFRJ. Rio de Janeiro, 2015

Madureira, S., Flores-Colen, I., Brito, J., Pereira, C. Maintenance planning of facades in current buildings. Construction and Building Materials, v. 147, pp 790-802, 2017.

Melo Júnior, C. M., Carasek, H. Índices de chuva dirigida direcional e análise do nível de umedecimento em fachadas de edifício multipavimento em Goiânia, GO. Ambiente Construído, Porto Alegre, v 11, n. 3 p. 23-37, Jul./Set. 2011.

Santos, D. G. Estudo da vida útil e degradação de fachadas em argamassa a partir da inspeção de edifícios. 2018. xv, 122 f., il. Dissertação (Mestrado em Estruturas e Construção Civil) Universidade de Brasília, Brasília, 2018.

Santos Netto, C. J. Análise quantitativa da degradação de fachadas em revestimento cerâmico: estudo de caso em edifícios de Belém- PA. 2018. 93 f. Dissertação (Mestrado) - Universidade Federal do Pará, Instituto de Tecnologia, Programa de Pós-Graduação em Engenharia Civil, Belém, 2018.

Van Mook, F. J. R. Driving Rain on Building Envelopes 2002. 198 f. Thesis (Ph.D. Thesis) Technische Universiteit Eindhoven, Netherlands, 2002. 